\title{
Comparative patterns of reading eye movement in Chinese and English
}

\author{
FUCHUAN SUN, MICHON MORITA, and LAWRENCE W. STARK \\ University of California, Berkeley, California
}

\begin{abstract}
Two very different language codes are exemplified by printed Chinese and English texts. Skilled native readers of each language have similar eye-movement patterns when care is taken to compare identical reading tasks and material and also to consider the Chinese multicharacter word. The similarity implies that both printed languages have been optimized to fit visual and oculomotor physiology and also higher level cognitive processes. Eye-movement recordings taken while subjects read from horizontal Chinese text, now widespread, and classical vertical text suggest that modern readers are now more at home with horizontal text; indeed, continued updating of reading skill appears necessary.
\end{abstract}

\section{Chinese Written Language}

The Chinese written language, with its 6,000 characters and 60,000 multicharacter words, is a major achievement of mankind. From an informational theoretic viewpoint, critical advances in man's evolution relate to the development of speech, of written language, and of printing; perhaps modern electronic communications and the digital computer provide another such step. Chinese characters are built from component radicals; 214 such radicals now form a standardized set and contain both ideographic and phonetic parts. A comparative discussion of the grammatical and linguistic features of Chinese and English is beyond the scope of this short research report; however, English is basically a phonetic language encoded in a true alphabet (Wang, 1973).

For our primary comparison of reading eye movements for Chinese versus English text, we presented scientific reading in order to reduce effects of cultural differences on text difficulty. Paragraphs of published Chinese translations of Scientific American were selected from articles that were fairly simple to understand for our readers, who were native Chinese professors and graduate students at the University of California, Berkeley. These were matched to the original English articles. In another experiment, secondarily comparing reading eye movements for horizontal versus vertical Chinese texts, we used classical Chinese poetry written vertically, perhaps a more difficult reading task.

The multicharacter Chinese word expresses complex meaning using combinations of single characters. They are similar to compound words in English, except that

\footnotetext{
We gratefully acknowledge partial support from the NCC 2-86 Cooperative Agreement with NASA-Ames Research Center and from the National Institute for Occupational Safety and Health. We also acknowlege the kind advice of Professor William S.-Y. Wang, Professor Kai Chu, and Dr. Phyllis Johnston. Fuchuan Sun was on leave from the Shanghai Institute of Physiology, Shanghai, China. Correspondence should be directed to: L. W. Stark, Neurology Unit, 481 Minor Hall, University of California, Berkeley, CA 94720.
}

in Chinese they are still written as discrete characters (Wang, 1973). On the average, the Chinese character group may be composed of approximately 1.5 characters, with the usual size being, perhaps, between one character $(55 \%)$ and two characters $(40 \%)$, with rather few three-character groups (5\%).

\section{The Heterogeneous Retina}

The small high-resolution central fovea is quite different in form and function from the low-resolution periphery, with its high sensitivity for detection, especially of moving objects. The retinal fovea is variously defined, depending upon the anatomical and physiological criteria chosen. The fixational fovea, within which gaze is maintained in fixation, is about $1 / 2^{\circ}$ (Ditchburn \& Ginsborg, 1953; Ratliff \& Riggs, 1950), the same visual angle as the sun or the moon. The visual acuity of healthy persons is about $20 / 10$, corresponding to a 2 -point resolution of $1 / 2^{\prime}$ of arc at the fovea, decreasing rapidly toward the periphery, where $20 / 200$ is attainable. It is generally accepted by reading experts that only the region within about $2^{\circ}$ from the fovea (O'Regan, 1983) is useful for reading letters. Perception of the external shapes of words (and characters) may also be helpful, and thus "near peripheral" vision (Bouman, 1950) may be involved in the perceptual reading task. Woodworth (1938) suggested that Chinese characters, with their boxlike shapes, might be better adapted to exploiting the circular fovea than English words, with their rectangular outlines.

\section{Reading Eye Movements}

The eye is stationary, resting in a fixational pause, about $90 \%$ of the time during a reading task (Tinker, 1936). Rapid saccadic eye movements take about $20 \mathrm{msec}$ for a $3^{\circ}$ jump; thus, four such movements divert only $10 \%$ of each second from reading time. Reading eye movements form a stereotyped pattern consisting, in large part, of a series of small, $2^{\circ}-4^{\circ}$, rightward- or forward-moving progressive saccades, jumping from word to word and 
often skipping smaller common words. When the end of the line is reached, a larger leftward saccade (about one column-width in amplitude) jumps about $10^{\circ}$ to the beginning of the next line; here, the retinal periphery participates in accurately executing the return-sweep saccade. These return-sweep saccades are often followed by small corrective saccades that readjust eye position to the beginning of the next line. About $5 \%$ to $20 \%$ of the time, regression saccades, moving leftward or backward, occur (Alder-Grindberg \& Stark, 1978); these saccades probably serve a grammatical or syntactical function. The periphery is used to direct saccadic eye movements, and the fovea is used to process high-resolution linguistic information and other detail.

A nominal reading rate for English might be 234 words/min (McConkie, 1983). Thus, a temporal decision determines the fixation duration (average value about $250 \mathrm{msec}$ ) and an amplitude decision determines the motor span (average value about 1.3 words) (McConkie, 1983). Together (1/fixation duration $x \operatorname{span} \times$ $60 \mathrm{sec} / \mathrm{min}$ ), duration and span determine the forward reading rate ( 312 words $/ \mathrm{min}$ ). The decisions may be controlled by peripheral visual clues (next word length) or by cognitive clues (expectation from context) (Hochberg, 1970), or even by a preprogrammed pattern (Levy-Schoen, 1981). If $15 \%$ of the time was used for return sweeps and $10 \%$ of the time for regressions, then the net reading rate would be less (234 words/min). Recent evidence (Carpenter \& Just, 1977) suggests that immediate processing of linguistic information occurs during each fixation in reading, providing the advantage of immediacy together with the disadvantage of sequential decision making. Topdown processing, such as generating important a priori guesses from context and then only roughly checking word shapes, apparently serves to bring reading speeds up to 300-400 words/min.

Levy-Schoen (Levy-Schoen \& O'Regan, 1979) has argued against facile acceptance of nonreading perceptual experiments, that is, using tachistoscopic presentation, as only indirectly applicable to reading; we have therefore turned to comparative studies of natural reading eyemovement patterns of persons naturally reading the same materials in Chinese and English.

\section{METHOD}

Our subject group consisted of four skilled native Chinese readers and eight other native Chinese who had been in the United States for a considerable time and who had been reading mainly English during that period. Another group consisted of eight readers of English, volunteers from among our laboratory colleagues and thus familiar with the nature of the experimental apparatus. Questioning afterward determined that both groups easily understood the text material. Laboratory methods for measuring eye movements included an infrared television eye monitor (Myers et al., 1981), infrared photocells (Stark, Vossius, \& Young, 1962), and an online digital computer system with special software for editing and analyzing the data.

\section{RESULTS}

\section{Horizontal Chinese Text}

The eye-movement pattern of Chinese reading (Figure 1) was very similar to that well known for reading Western languages such as English. The form of the return sweep and the corrective saccade, if the return sweep is not accurately located at the beginning of the line, are also similar to English in a qualitative sense. Furthermore, the same paucity of regressions exists in both sets of reading for our material. Not only are the patterns similar in terms of the various eye-movement components and their outward appearance in various graphical displays, but the quantitative measures are also quite close (see Table 1). For example, the durations of fixational pauses are very similar for subjects reading horizontal Chinese text and horizontal English text, 260 and $270 \mathrm{msec}$, respectively. We measured the length of the English original text in number of words and the length of the Chinese translation in number of characters; the average English word was equivalent on all three sets of
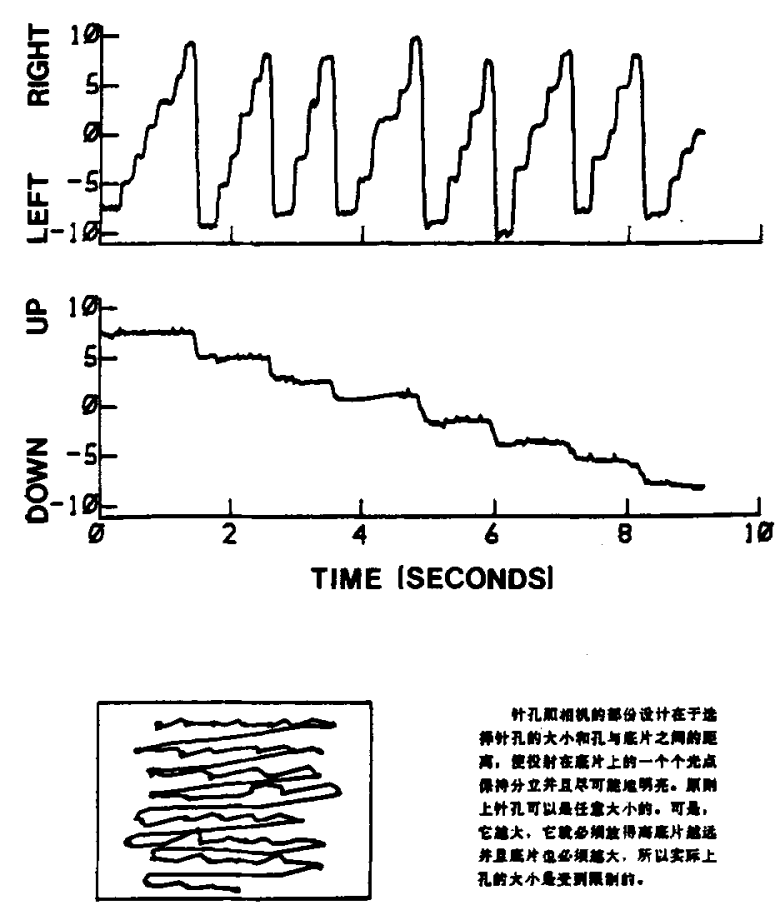

Figure 1. Eye-movement pattern for horizontal Chinese text. There is a multiply interrupted saccadic progression to the right, with fixations on many words, and a rapid saccadic return sweep to the left (lower left box, which is approximately $26^{\circ} \times 18^{\circ}$ in size). If superimposed on the text (lower right), the record could give an indication of the relative precison of the eye positioning. When displayed as horizontal angle in degrees as a function of time in seconds, the record looks like a succession of staircases, representing the saccadic motion of the eye from word to word (upper trace). When portrayed as vertical angle as a function of time, the record looks like a rather slow staircase, representing the vertical saccadic motion of the eye from line to line (middle trace). 
Table 1

Quantitative Measures of Reading-Eye-Movement Patterns

\begin{tabular}{|c|c|c|c|}
\hline & $\begin{array}{l}\text { Fixation } \\
\text { Duration } \\
\text { (second) }\end{array}$ & $\begin{array}{c}\text { Span } \\
\text { (words or characters } \\
\text { per fixation) }\end{array}$ & $\begin{array}{c}\text { Reading Rate } \\
\text { (words or characters } \\
\text { per minute) }\end{array}$ \\
\hline English & 0.27 & 1.8 & 380 \\
\hline $\begin{array}{l}\text { Chinese: Horizontal } \\
\text { (characters) } \\
\text { Chinese: Horizontal } \\
\text { (equivalent words) }\end{array}$ & $\begin{array}{l}0.26 \\
(0.26)\end{array}$ & $\begin{array}{l}2.6 \\
1.7\end{array}$ & $\begin{array}{l}580 \\
390\end{array}$ \\
\hline $\begin{array}{l}\text { Unskilled Chinese } \\
\text { (characters) } \\
\text { Unskilled Chinese } \\
\text { (equivalent words) }\end{array}$ & $\begin{array}{c}0.29 \\
(0.29)\end{array}$ & $\begin{array}{l}1.7 \\
1.1\end{array}$ & $\begin{array}{l}360 \\
240\end{array}$ \\
\hline $\begin{array}{l}\text { Chinese: Vertical } \\
\text { (characters) } \\
\text { Chinese: Vertical } \\
\text { (equivalent words) }\end{array}$ & $\begin{array}{c}0.29 \\
(0.29)\end{array}$ & $\begin{array}{l}1.2 \\
0.8\end{array}$ & $\begin{array}{l}260 \\
170\end{array}$ \\
\hline
\end{tabular}

texts to approximately 1.5 Chinese characters. This 1.5 factor from translation comparison is similar to the $\mathbf{1 . 5}$ factor for the average character group size in the hypothetical calculation given in the introduction.

If we now consider the Chinese reading pattern in terms of "equivalent words," that is, after adjustment for the 1.5 factor, we find that other quantitative measures also become similar. The span, or forward jump, distance of the forward reading saccade is approximately 1.7 Chinese equivalent words for skilled Chinese readers and approximately 1.8 English words for American readers. There is some qualitative evidence in our reading records that indicates that the eye usually fixates once per multicharacter word. This detailed observation supports the overall statistical data. Reading rate also comes out to be very similar: 390 equivalent words in Chinese per minute versus 380 English words per minute.

\section{Vertical Chinese Text}

Vertical text was the most common form of printing in China until the second quarter of this century. At the present time, horizontal Chinese text is more prevalent, especially for scientific reading material, such as was employed here. The reading pattern for vertical text is remarkably similar to that of reading horizontal text, except with the vertical and horizontal directions interchanged and, of course, with columns read from right to left (Figure 2). The return sweeps are upward to the top of the next leftward column. With these adjustments for directionality in mind, we compared the various quantitative measures for vertical Chinese text with those for horizontal Chinese text and English (Table 1). The span is only about half of the span for horizontal Chinese text or for English. The duration of fixations is about $10 \%$ larger-290 msec for vertical Chinese text, but 260 and $270 \mathrm{msec}$ for horizontal Chinese and English reading, respectively.

\section{DISCUSSION}

\section{Equivalent Word}

The 1.5 factor for the multicharcter nature of the Chinese equivalent word rests on several bases, independent of eye-movement studies. We measured the number of characters in the Chinese translation and the number of words in the English original to get consistently 1.5

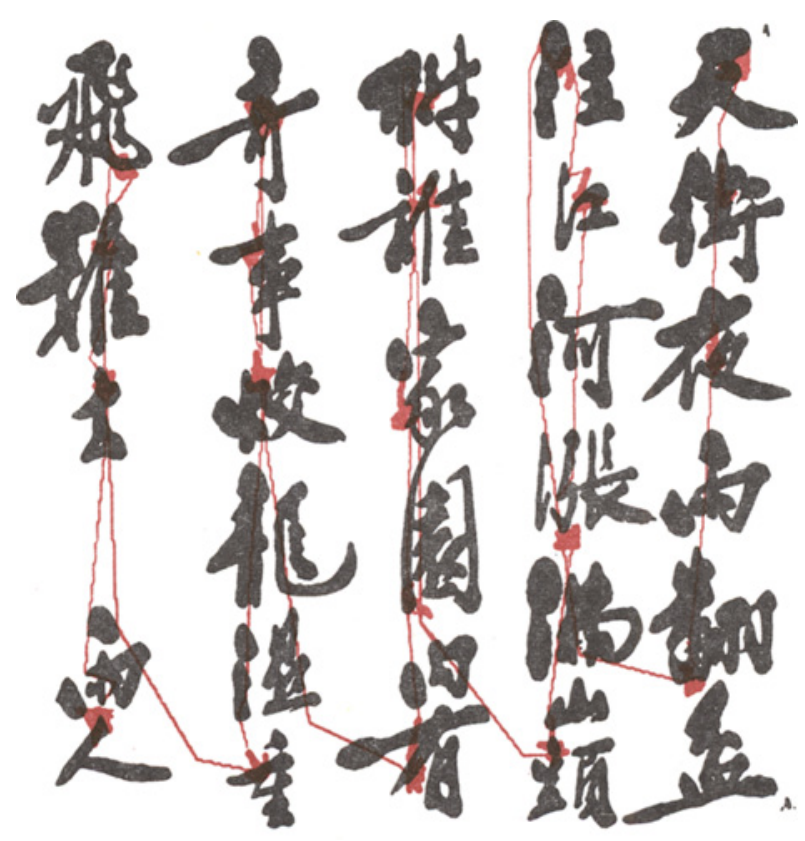

Figure 2. Reading eye-movement pattern for vertical Chinese text. Eye movement (red) is superimposed over this classical Chinese poem written in the vertical format. Fixation pauses occur sequentially from top to bottom, with line return saccades occurring from bottom to top. 
characters per equivalent word. Linguistic studies (Wang, 1973) further emphasize the similarity of the multicharacter group and the equivalent word in Chinese. This 1.5 factor, that about 1.5 Chinese characters are equivalent to one English word, will be used below in comparing reading eye movements for Chinese versus English.

\section{Similarities in Reading Eye Movements}

Similarities in reading eye movements for Chinese and English are noted in the general stereotypic patterns and in the fixation durations, even without using the 1.5 factor. With the 1.5 factor, other quantitative measures also come into line. The spans are about 1.7 Chinese equivalent words and 1.8 English words (see Table 1). The reading rates were about 385 equivalent words per minute for Chinese and 380 words per minute for English for the same scientific textual material (Table 1). This comparability in reading eye-movement patterns and quantitative measure was established by having similarly scientifically trained readers reading Chinese translations or original semipopular scientific text from Scientific American articles that might be expected to cut across cultural boundaries.

In the past 30 years, Chinese printing has shifted from a vertical-line format to a horizontal-line format. In the 1920s, several studies (Chen \& Carr, 1926; Shen, 1927; $\mathrm{Tu}, 1930$ ) found Chinese readers to be more skillful in reading the vertical format; we found our readers to be much less adept at reading vertically: 256 equivalent words per minute versus 386 equivalent words per minute horizontally (Table 1). That the equivalent vertical text was read more slowly, even by our skilled (horizontal) readers, suggests the highly skilled nature of reading Chinese.

Also of interest was the considerable comparative lack of skill in reading Chinese by native Chinese readers who had emigrated to California and had read mainly English for the previous 5 years. Their reading rate was only 240 equivalent words per minute versus 386 for native Chinese in California for 2 years or less (Table 1).

Differences in reading eye movements for Chinese and English were noted in our study. It has been suggested that the shape of the Chinese character fits the nonastigmatic fovea better than the shape of English words (Woodworth, 1938). The spans, although equal in meaningful content, 1.7 equivalent Chinese words versus 1.8 English words, are different in visual angle. The span, measured in degrees, for Chinese readers was about $15 \%$ smaller than the span for English readers under our experimental conditions. Miles and Shen (1927), too, noted a larger number of saccades per line of Chinese print. However, it should be pointed out that scale is not a primary variable in determining the overall patterning of reading eye movements. In our experiments, we used $5^{\circ}, 11^{\circ}$, and $20^{\circ}$ printed page widths and found the reading rate and eye-movement pattern to be quite robust to scale expansion and diminution, confirming the classic studies of Javal
(1879) and Huey (1900), and the more recent results of O'Regan (1980) and Morrison and Rayner (1981).

What accounts for the close similarity in reading eyemovement patterns for such different languages as Chinese and English? Eye movements are probably optimized by evolution to serve the visual processes that occur while successively glancing or scanning a scene. The linguistic visual processes may be assumed to be derived from those subserving general vision.

Printed text and the art of the typographer have evolved under various social feedback mechanisms since early woodblock printing of Chinese and the use in Korea of moveable type, which had been invented by the Chinese, to print 38 volumes of Chinese classics in 1104 (Carter, 1955). A similar cultural evolution has occurred in the printing of Western literature. Certainly, one of the forces shaping the page of print was adjustment to the physiological and control features of the eye movements; Javal (1878) gives an extensive discussion of historical changes in text style and their contributions to legibility, as well as suggestions for more changes. In approaching this problem, we also calculated linear and areal density of Chinese equivalent words and compared this to density of English words. With the 1.5 equivalent word factor, packing densities are similar-Chinese is 1.3 times denser in linear dimension and English 1.1 times denser in areal dimension. Of course, we rely here on some normalization by printers, typographers, and editors of the English and Chinese versions of the Scientific American articles, who likely arranged the two printed formats to suit the same physiological sensory and motor visual process.

Probably eye-movement accuracy is matched to a requirement for fitting an ideal visual object into the fovea, and then the word size is adapted toward this ideal visualobject size. One might consider that increasing the size of characters would improve the visual perception process, and that perhaps even decreasing the size of the character might allow the required eye movements to be smaller. Of course, there are some small sizes that might introduce inaccuracies and irregularities into the eye-movement pattern. The width of the column of text is probably governed by a similar optimization process. As the width is increased, the number of return sweep saccades per forward saccade is decreased, thereby saving time. However, decreasing column width decreases the number of position errors and, thus, position correction fixations. The development of printed language was probably directed by optimization processes to create excellent codes. Two such very different, but excellent, codes are Chinese and English.

Finally, we may consider the higher level cognitive processes as rate limiting. If we consider reading as an informational channel in the Shannon sense (Schalkwijk \& Kailath, 1966a, 1966b; Shannon, 1956; Stark \& Theodoridis, 1973), we see that, not only in visual perception and cognitive language processing, but also in the early stages of the channel, eye movements play an es- 
sential role. One might expect that each of these elements in the reading channel would be roughly matched so that none of the three elements is rate limiting.

Of course, the modern approach to reading is that reading is a top-down pattern-recognition process (Stark, 1967; Stark \& Ellis, 1981). Another way of looking at the top-down guessing process is to consider Shannon's noiseless feedback theorem. Shannon pointed out that even if we have noiseless feedback (feed forward) from the receiver to the source of the code traveling to the channel, we cannot increase channel capacity. However, what we can do is simplify the code wherewith we can achieve channel capacity. One may consider the guesses of the skilled intelligent reader as a kind of noiseless feedback from the a priori guess of the subject to the estimate of how close the guess was to the word being read. In this way, laborious bottom-up visual processing is circumvented and the more efficient code is employed. Thus, the reader uses all his intellectual skills and his knowlege of the context of the reading material in "guessing" the words that are highly likely to come up next in the sentence. In this way, the eye movements enable the visual perceptual process to get just the barest glimpse of the shape of the word and perhaps a few essential letters in order to confirm the guesses. This is the process that leads to excellence and high reading speeds.

Many questions have been raised during this research comparing Chinese and English reading. Perhaps a whole new dimension in comparative eye movements and reading performance will be developed in the near future.

\section{REFERENCES}

Alder-Grindberg, D., \& StaRK, L. (1978). Eye movements, scanpaths, and dyslexia. American Journal of Optometry and Physiological Optics, 55, 557-570.

Bouman, M. A. (1950). Peripheral contrast thresholds of the human eye. Journal of the Optical Society of America, 40, 825-833.

Carpenter, P. A., \& JuST, M. A. (1977). Reading comprehension as eyes see it. In M. A. Just \& P. A. Carpenter (Eds.), Cognitive processes in comprehension (pp. 109-139). Hillsdale, NJ: Erlbaum.

CARTER, T. C. (1955). The invention of printing in China and its spread westward (2nd ed., pp. 211-237, L. C. Goodrich, Ed.). New York: Ronald Press.

Chen, L. K., \& CARr, H. A. (1926). The ability of Chinese students to read in vertical and horizontal directions. Journal of Experimental Psychology, 9, 110-117.

Ditchburn, R. W., \& GinsBorg, B. L. (1953). Involuntary eye movements during fixation. Journal of Physiology, 119, 1-17.

HochBERG, J. (1970). Components of literacy: Speculation and exploratory research. In H. Levin \& J. P. Williams (Eds.), Basic studies on reading. New York: Basic Books.

HuEY, E. B. (1900). On the psychology and physiology of reading. American Journal of Psychology, 11, 283-302.

JAVAL, K. E. (1878). Essai sur la physiologie de la lecture. Annales d'Oculistique, 79, 98-117.

JAVAL, K. E. (1879). Essai sur la physiologie de la lecture. Annales d'Oculistique, 82, 243-253.
LEVY-SCHOEN, A. (1981). Flexible and/or rigid control of oculomotor scanning behavior. In D. F. Fisher, R. A. Monty, \& J. W. Senders (Eds.), Eye movements: Cognition and visual perception (pp. 299314). Hillsdale, NJ: Erlbaum.

LeVy-Schoen, A., \& O'REgAN, K. (1979). The control of eye movements in reading. In P. A. Kolers, M. E. Wrolsad, \& H. Bouma (Eds.), Processing of visual language (pp. 7-36). New York: Plenum Press.

McConkIE, G. W. (1983). Eye movements and perception during reading. In K. Rayner (Ed.), Eye movements in reading (chap. 5, pp. 6596). London: Academic Press.

Miles, W. R., \& SHEN, E. (1927). Photographic recording of eye movements in the reading of Chinese in vertical and horizontal axes; methods and preliminary results. Journal of Experimental Psychology, 10 , 158-183.

Morrison, R. E., \& Rayner, K. (1981). Saccade size in reading depends upon character spaces and not visual angle. Perception \& Psychophysics, 30, 395-396.

Myers, G. A., Anchetta, J., Hannaford, B., Peng, P., Sherman, K., Stark, L., SUN, F., \& Usul, S. (1981, June). Pupillometry, a bioengineering overview. In I7th Annual Conference on Manual Control (pp. 525-536). Pasadena, CA: Jet Propulsion Laboratory.

O'REGAN, K. (1980). The control of saccade size and fixation duration in reading: The limits of linguistic control. Perception \& Psychophysics, 28, 112-117.

O'REGAN, J. K. (1983). Elementary perceptual and eye movement control processes in reading. In $\mathrm{K}$. Rayner (Ed.), Eye movements in reading (chap. 7, pp. 121-139). London: Academic Press.

Ratliff, F., \& RigGs, L. A. (1950). Involuntary motions of the eye during monocular fixation. Journal of Experimental Psychology, 40, 687-701.

SchalkwiJk, J. P. M., \& Kailath, T. (1966a). A coding scheme for additive noise channels with feedback: 1 . No bandwidth constraint. IEEE Transactions on Information Theory, IT-12, 172-182.

SchalkwiJ, J. P. M., KaIlath, T. (1966b). A coding scheme for additive noise channels with feedback: II. Band-limited signals. IEEE Transactions on Information Theory, IT-12, 183-189.

Shannon, C. E. (1956). The zero-error capacity of a noisy channel. IRE Transactions on Information Theory, IT-2, 8-19.

SHEN, E. (1927). Analysis of eye movements in the reading of Chinese. Joumal of Experimental Psychology, 10, 158-183.

STARK, L. (1967). Pattern recognition as a model for neurophysiology. In D. M. Ramsey (Ed.), Information and control processes in living systems (pp. 85-103). New York: New York Academy of Sciences.

STARK, L., \& Ellis, S. (1981). Scanpaths revisited: Cognitive models of direct active looking. In D. F. Fisher, R. A. Monty, \& J. W. Senders (Eds.), Eye movements: Cognition and visual perception (pp. 183226). Hillsdale, NJ: Erlbaum.

STARK, L., \& THEODORIDIS, G. C. (1973). Information theory in physiology. In J. H. U. Brown \& D. S. Gann (Ed.), Engineering principles in physiology (Vol. 1, pp. 13-32). New York: Academic Press.

Stark, L., Vossius, G., \& Young, L. R. (1962). Predictive control of eye tracking movements. I.R.E. Transactions on Human Factors in Electronics, HFE-3, 52-57.

TINKER, M. A. (1936). Time taken by eye movements in reading. Joumal of Genetic Psychology, 48, 468-471.

Tu, H. T. C. (1930). The effects of different arrangements of the Chinese language upon speed and comprehension of silent reading. Journal of Genetic Psychology, 38, 321-327.

WANG, W. S.-Y. (1973). The Chinese language. Scientific American, 228, 50-60.

WOODWORTH, R. S. (1938). Experimental psychology (chap. 28). New York: Holt.

(Manuscript received November 14, 1983; revision accepted for publication March 25, 1985.) 